\title{
Heteronomía, progresismo y políticas públicas en América Latina ${ }^{1}$
}

\section{Heteronomy, Progressivism and Public P olicies in Latin America.}

\author{
Guillermo Alfredo Johnson ${ }^{2}$ \\ Docente e investigador, Universidade Federal do Maranhão, São Luís, Brasil \\ guijohnson@uol.com.br \\ ORCID: https://orcid.org/0000-0002-6508-3105
}

\section{Marcos Antonio da Silva}

Docente e investigador, Universidade Federal da Grande Dourados, Dourados, Brasil

marcossilva@ufgd.edu.br

ORCID: https://orcid.org/0000-0003-1196-2814

Recibido: 16-02-2018 Aprobado: 20-03-2019

1 Este artículo hace parte de las elaboraciones resultantes del trabajo investigativo de los proyectos "Estado e políticas públicas na América Latina: diretrices contemporáneas das políticas governamentais" y "Dinâmicas neoliberais na América Latina: Estado e democracia no século XXI", costeadas con recursos y medios de la Universidade Federal da Grande Dourados, de Brasil.

Doctor en Sociología Política.

3 Doctor en Estudios sobre la Integración de América Latina. 


\section{Resumen}

La historia de inserción de América Latina en el contexto del imperialismo, y su paulatina financiarización, incitan a analizar la acción estatal en el presente siglo. En este estudio buscamos evidenciar la persistencia del carácter heterónomo de las directrices de las políticas públicas en América Latina, inclusive durante el período de los gobiernos progresistas. Este ensayo teórico se sustenta en teorías críticas enfatizando un desarrollo contextual de la dinámica del sistema internacional. Verificamos que, a partir de la inserción heterónoma de los países latinoamericanos, esas características persisten en el inicio de este siglo, con la ascensión de gobiernos progresistas, aunque eventualmente políticas públicas sectoriales apuntaron caminos alternativos. En los últimos años se fortalece un sesgo articulado por neoliberales y conservadores en los gobiernos nacionales que pugna por políticas públicas crecientemente heterónomas.

Palabras clave: Estado; políticas públicas; América Latina; gobierno; heteronomía.

\section{Abstract}

The analysis of the historical dynamics of insertion of Latin America in the context of imperialism and its gradual financialization, incites us to evaluate the state's actions in the present century. In this study we seek to demonstrate the persistence of the heteronomous character of the directives of the national policies in Latin America, even during the period of progressive governments. This theoretical essay is supported by critical theories emphasizing a contextual development of the dynamics of the international system. We assess how, since the heteronomous insertion of the Latin-American countries, these characteristics persevere to the beginning of this century, even with the ascension of progressive governments, although eventually some sectorial political policies aimed at alternative ways. In recent years, a bias articulated by neoliberals and conservatives in national governments has been strengthened, which is struggling for increasing heteronomous public policies.

Keywords: State, Public Policies, Latin America, Government, Heteronomy.

¿Cómo citar este artículo? / How to quote this article?

Johnson, G. A. y da-Silva, M. A. (2019). Heteronomía, progresismo y políticas públicas en América Latina. Sociedad y economía, (37), 71-86. https://doi.org/10.25100/sye.voi37.7822 


\section{Introducción}

En las últimas tres décadas, la discusión en torno de alternativas societarias fue sistemáticamente confrontada por una corriente de pensamiento crecientemente hegemónica que retomó una versión del pensamiento liberal, cuyas ideas eran irrealizables ya en su origen, en los siglos XVIII y XIX, tornándose más evidente en la hodierna complejidad del capitalismo financiero.

Consideramos que no es posible analizar la dinámica estatal en los países latinoamericanos sin una comprensión evidentemente jerárquica del sistema mundial. La subordinación y las relaciones de dominación que configuran la relación imperialista en la periferia necesariamente se manifiestan en el seno del Estado, erigiéndose en heteronomía en el ámbito nacional, al replicar de forma mediatizada las directrices políticas provenientes de los imperativos hegemónicos.

Las primeras elaboraciones teóricas del concepto de imperialismo remontan al siglo XIX, con la obra de Rudolf Hilferding, "El Capital Financiero". En la última década del pasado siglo el concepto de globalización buscó establecerse con la aspiración de relativizar las jerarquías que organizan el sistema global (Amin, 2001). Sin embargo, con la multiplicación de las crisis económicas y políticas, las movilizaciones multitudinarias y las guerras, a partir de este milenio, la necesidad de explicaciones macro restaura la importancia del concepto de imperialismo. En ese sentido, consideraremos en estas reflexiones teóricas a América Latina a partir de la perspectiva del imperialismo, como parte de la división internacional del trabajo, al mismo tiempo que, a partir de los países, la heteronomía se imbrica con la heterogeneidad en la arquitectura de las políticas públicas. En este análisis no enfatizaremos este último aspecto, precisamente por la complejidad que demandaría dicho planteamiento.

Las teorías del imperialismo permiten vincular la relación jerárquica a nivel global con la permeabilidad en sus políticas nacionales, lo cual incluye a los países latinoamericanos. Este ensayo teórico tiene como objetivo evidenciar la persistencia del carácter heterónomo de las directrices de las políticas públicas 4 en América Latina, inclusive durante el período de los gobiernos progresistas. Así, las reflexiones teóricas contribuyen para examinar la traducción que las políticas públicas nacionales conforman al considerar las directrices generales para los países de la región en la última década y media. Para tal fin, en primera instancia, debatimos la actualidad del imperialismo y su manifestación como heteronomía en ámbitos nacionales en Latinoamérica; a seguir, analizamos las traducciones de esa relación jerárquica en lo que se refiere a las políticas públicas y, finalmente, realizamos apuntamientos generales de la manifestación de esa condición subalterna en el periodo considerado como progresista. Como forma de reflexión final, tejemos consideraciones que remiten a una persistencia de gobiernos que fortalecen directrices estatales heterónomas y marcados rasgos oligárquicos, sin por eso mitigar las luchas de nuevos y antiguos sectores de clases.

\section{Imperialismo y heteronomía en América Latina}

Son recurrentes análisis políticos y económicos que efectúan críticas puntuales o presentan fallas como meras contradicciones. En esa senda, el aumento de la miseria y el desempleo a nivel mundial es interpretado como malestar pasajero a ser mitigado con políticas compensatorias; en el comercio internacional los países periféricos proponen una abstracta igualdad en el mercado mundial, visando reducir el creciente abismo Norte-Sur a través de la reducción del

4 Las directrices de las políticas públicas se refieren a los procesos decisorios que orientan su diseño institucional, las modalidades preferenciales de atención a las necesidades sociales. Al considerar el policy cycle, asimilamos el concepto de directrices al de polity, que concierne a las reglas fundamentales del juego político, a la estructuración del Estado, resultante de los embates entre los sectores sociales que interfieren en el proceso decisorio conyuntural en que ellas actúan (Johnson y Silva, 2016). 
viejo y nuevo proteccionismo; al mismo tiempo en que las grandes potencias económicas intentan disimular la rivalidad interimperialista a través de la conformación de bloques regionales. Los aspectos antes mencionados, entre otros, conducen a pensar que la realidad actual debe ser considerada esencialmente nueva, posible de ser comprendida solamente a partir del concepto de globalización. Por lo tanto, no tendría sentido mencionar cualquier afirmación de concentración o centralización del poder, el dominio u opresión de un Estado por otro.

Frecuentemente también, la negación de la vigencia del concepto de imperialismo está relacionada con las diferentes interpretaciones acerca del significado del mismo. Es fundamental recordar que, de acuerdo con Lenin (1986), esa arquitectura del poder no se refiere a un fenómeno meramente cultural o a una política determinada, preferida por el capital. El dominio de una nación sobre otra, la tendencia para las invasiones y ocupaciones, así como la política colonial, serían expresiones de las transformaciones objetivas en la dinámica del proceso de producción y reproducción del capital. La configuración del imperialismo se erige en un camino inexorable a partir de determinado nivel de desarrollo del capitalismo. Para Lenin, el imperialismo es el propio capitalismo contemporáneo, cuando la monopolización, la concentración de la economía pasa a dominar a libre competencia.

En lugar de la propalada noción lineal de desarrollo que transmitía un proceso por etapas de los países dependientes en dirección a un supuesto destino, que sería el modelo de desarrollo del "capitalismo avanzado", Lenin evidenció cómo el imperialismo conduce, necesariamente, al recrudecimiento de la ley del desarrollo desigual y combinado entre países y regiones. De este modo, mostró cómo el subdesarrollo relativo de ciertos países era una precondición para el desarrollo de otros. Tales contradicciones enunciadas por Lenin hace décadas, posteriormente constatadas por las elaboraciones de Fernandes (1981a; 1981b) y Marini (1992), entre otros, se agudizan con la dinámica de procesos y mecanismos que conforman el imperialismo contemporáneo (Boron, 2012).
Es posible afirmar que en la presente fase imperialista del capital, fundamentado pertinentemente en las relaciones indisociables entre política y economía, las dos formas de ejercicio de la dominación -la pacífica y la no pacífica- están imbuidas por la lógica de conservación del poder hegemónico (Lenin, 1986). Evidentemente, no se está proponiendo una transposición automática de la configuración del sistema mundial de un siglo atrás con la presente realidad. Estamos afirmando que es pertinente caracterizar la presente fase del capitalismo como una continuación, en esencia, de la relación imperialista ya vigente en el inicio del siglo pasado (Harvey, 2004; Wood, 2014).

Este milenio restituye el dominio coercitivo hegemónico, con cada vez más amplias y crueles guerras que se abaten sobre regiones que hace siglos no vivenciaban tamaña violencia (siendo el caso más evidente el de Oriente Medio). Aliado a un intenso poder militar -centralizado en los Estados Unidos de América (EUA)- el creciente poder financiero, condensado en un puñado de bancos y correctoras, así como el aumento de la amplitud e intensidad de la concentración de la producción de alimentos, tecnología y energía por un reducido número de empresas transnacionales, cuestionan los fundamentos de una posible sociedad mundial harmónica rumbo al progreso o al desarrollo sostenible. Si por algunos intervalos, en este último período hubo señales de construcción de un orden multipolar en el sistema internacional, acciones de la fuerza hegemónica (EUA) no dejaron dudas en cuanto a la jerarquía vigente 5 .

La pugna incesante por la apropiación de la producción social de la riqueza restituye la im-

5 Sobre la historia de la ascensión y persistencia de los Estados Unidos como país hegemónico hay vasta bibliografía: para el caso específico de América Latina (Schoultz, 1999; Suárez Salazar, 2003; Ayerbe, 2002), así como en la construcción de su poder global (Moniz Bandeira, 2005; Mészáros, 2007; Wood, 2014), para citar algunos. Al mismo tiempo es indispensable mencionar que en las dos décadas del siglo XXI se erigen nuevas amenazas a la hegemonía estadounidense. Es el caso de China y también de las diversas disputas geopolíticas de la contemporaneidad. 
portancia del concepto de lucha de clases. De esta forma, conflictos, guerras, invasiones, crisis políticas y económicas no son anomalías o elementos extraños, sino características constituyentes de este sistema social desigual, fundado en la explotación y en diversos métodos de manipulación y violencia para ejercer la dominación.

Para tener un sucinto panorama de la dimensión de la problemática contemporánea es preciso apuntar que la suma de las riquezas de 62 personas en el mundo es igual a la renta de $50 \%$ de la población mundial más pobre: 3,6 mil millones de personas; de acuerdo con las mismas fuentes de información, al compararla con los cinco años anteriores, la riqueza de esas 62 personas aumentó en $44 \%$ (Documento Informativo de OXFAM 210, 2016). Esa realidad mundial se despliega en América Latina con particular intensidad, como expresión de la desigualdad en la distribución de la riqueza mundialmente producida:

En 2014, el 10\% más rico de la población de América Latina había amasado el 71\% de la riqueza de la región. Según los cálculos de Oxfam, si esta tendencia continuara, dentro de solo seis años el 1\% más rico de la región tendría más riqueza que el $99 \%$ restante (CEPAL y OXFAM, 2016, p. 6).

Ese escenario es el corolario de las directrices de las políticas que se propagaron por el globo a partir de 1970, frecuentemente denominadas neoliberales, que pueden ser resumidas por la abolición de los controles sobre los flujos financieros transnacionales, la creciente privatización masiva de los activos públicos y la desregulación de diversas esferas de servicios y derechos conquistados históricamente. Dichas acciones conducidas rígidamente a partir del Estado (Boron, 2003; Harvey, 2008; Jessop, 2015).

Al mismo tiempo, y en apretada síntesis, la derrota coyuntural de los trabajadores se inicia con la implementación del toyotismo y de su envolvimiento manipulador. En consecuencia, verificamos la derrota de los sindicatos en los países centrales y la imposición gradual de una intensificación de la precarización de los medios de subsistencia de la mayoría de la población (Antunes, 2011). Ese escenario es reforzado por la derrocada del Muro de Berlín, la desagregación y fin de la Unión Soviética, que fortalece la propaganda del fin del socialismo y de la difundida imposibilidad de construcción de sociedades alternativas al capitalismo; esa onda ideológica -asociada a la potente ofensiva del capital sobre el trabajo con vistas a su reproducción ampliada- presenta altos y bajos, vinculados a la capacidad de reacción regionalizada que los trabajadores demuestran ante esas envestidas. Los trabajadores carecen en el presente de horizontes organizativos que permitan confrontar la unidad de las personificaciones del capital -entre las que podemos destacar el FMI y el Banco Mundialque contribuyen para la homogeneización de las condiciones de acumulación del capitalismo global, regulando la concesión de préstamos, presionando por la reducción de los sueldos y cortes en los recursos para las políticas sociales, no solamente en los países periféricos.

El actual régimen de acumulación capitalista presenta predominancia financiera, con todas sus implicaciones para la inversión productiva (Chesnais, 1998; 2003). Lo que eminentemente mueve al capitalismo en la fase contemporánea son los dividendos generados en la esfera financiera, a través de los innúmeros instrumentos forjados desde la liberalización de los capitales en el inicio de los años 1980: títulos, derivativos, acciones, la bursatilización de las deudas -principalmente de la deuda pública-. En esa transformación del patrón de acumulación capitalista son las nuevas instituciones financieras, los fondos de pensión, los mutual funds, las correctoras, quienes se transforman en los principales protagonistas del sistema global, acaparando $\mathrm{y}$, por periodos, relegando a un segundo plano el sector productivo, incluso las grandes transnacionales (Lapavitsas, 2011). La actual configuración del mercado financiero potencializa la concentración de la riqueza, penalizando severamente las economías periféricas. Los procesos en curso no son irreversibles y representan una correlación de fuerzas sociales en que los sectores financieros consiguieron una hegemonía, emprendida por los EUA (país que más se beneficia de este régimen de acumulación). 
Esa nueva ofensiva del capital se materializa en la coyuntura favorable a la implementación de las políticas neoliberales a nivel mundial.Vivenciamos una nueva escalada de la política imperialista, en la cual "[...] predominan total o ampliamente los intereses de las élites gubernamentales y de las clases dominantes mundiales" (Ianni, 2004, p. 142). Es fundamental resaltar que el actual escenario es fruto de una correlación de fuerzas desfavorable para la clase trabajadora, configurando una constelación diferenciada para este momento del capitalismo que, entrando en un nuevo ciclo de acumulación, presenta otras formas sociales y culturales, en el ámbito de la ofensiva que los sectores dominantes promueven a nivel global (Harvey, 2009). Al mismo tiempo, las formas de dominación, en el ámbito de la fase neoliberal del capitalismo, poseen adaptaciones en su trayectoria de poco más de cuatro décadas en Latinoamérica, por ejemplo, en la creciente incorporación de las políticas de transferencia condicionadas de rentas como componente social de su agenda hegemónica (Brenner, Peck y Theodore, 2010; Puello-Socarrás y Gunturiz, 2013).

En el ámbito de la dominación capitalista vinculados con las correlaciones de fuerzas geopolíticas en dinámica histórica- es posible verificar en el periodo reciente una nueva tentativa de reconversión colonial, encarnada en la ofensiva político-económica que el bloque en el poder internacional y sus aliados locales realizan sobre las conquistas de los trabajadores en las últimas tres décadas. Aunque la relación de subordinación de los países latinoamericanos en el sistema internacional sea continua, no significa ausencia de momentos de tensión, tentativas de diversas naciones en varios momentos de construir políticas emancipadoras $\mathrm{o}$, al menos, con tentativas independientes y/o nacionalistas; dichas relaciones están en el seno de una disputa inagotable, en el ámbito de la cual los métodos no violentos y los violentos pueden ser usados de acuerdo con la necesidad de manutención hegemónica (Ceceña, 2005). Evidentemente, la configuración de las relaciones internacionales presenta modificaciones, propias de la realidad modelada por la acumulación del capital y de las luchas de resistencia y oposición a sus imperativos.
En ese sentido, consideramos que los cinco atributos del imperialismo ${ }^{6}$ se encuentran plenamente vigentes, siendo que comprobamos la creciente monopolización de la producción de bienes y servicios a nivel internacional; que el capital financiero desempeña una ascendente importancia en la fase contemporánea de acumulación (mundialización); se consolida la exportación de capitales (que se expresa, entre otros, en la Inversión Externa Directa); la formación de asociaciones internacionales monopolistas de capitalistas (Banco Mundial [BM]; Fondo Monetario Internacional [FMI]; Organización de las Naciones Unidas [ONU],); ; a partir del fin de la "bipolaridad mundial" se abre la disputa por la hegemonía a nivel global, actualmente ejercida por los Estados Unidos. Entre las cinco características esenciales del imperialismo, la última de ellas es de particular importancia para nuestro análisis: "A los numerosos 'viejos' motivos de la política colonial, el capital financiero ha añadido la lucha por las fuentes de materias primas, por la exportación de capital, por las 'esferas de influencia', [...] y, finalmente, por el territorio económico en general" (Lenin, 1986, pp. 157-8). Los procesos y mecanismos políticos y económicos son sistemáticamente activados para ejercer la dominación geopolítica.

En ese sentido, Panitch (2000) apunta, basado en Poulantzas, que el elemento que caracteriza la actual dominación imperialista reside en la inducción a la reproducción de la forma dominante de ejercicio del poder dentro de cada

6 Los aspectos que referimos se encuentran en Lenin (1986, pp. 114-24).

7 Es imposible explicar en este conciso escrito esta afirmación, pero solo para reflexionar observemos la composición del Consejo de Seguridad de la ONU, formado por un reducido número de países con poder de veto. Lo mismo puede ser pensado con relación a la política de derechos humanos, se aplica para todos los países, menos para los miembros del referido consejo.

8 La obra de Boron (2012) aborda la geopolítica de la dominación latinoamericana. En cuanto a las perspectivas de sucesión hegemónica en el sistema mundial, son estudiadas, con diferentes pronósticos, por Giovanni Arrighi e Immanuel Wallerstein. Mészáros (2007; 2011) analiza la dinámica de la hegemonía mundial, sin posicionarse respecto de eventuales sucesiones. 
formación nacional. Ya Fernandes (1979), al investigar sobre el papel de las burguesías de los países dependientes, afirmaba que "[...] como sucedía con las elites coloniales, se convertían en el eslabón interno de la dominación imperialista externa" (p. 40). En sus análisis sobre la revolución burguesa en atraso", sostiene que las burguesías nacionales optaron por tornarse socios menores del capital transnacional adhiriendo al carácter eminentemente autoritario de los Estados en los países dependientes; en última instancia, asimilando los valores e intereses del capital internacional. Esta condición subalterna obstruye persistentemente las tentativas desarrollistas en los países de revolución burguesa en atraso (Marini, 1992).

La heteronomía latinoamericana puede ser observada en un complejo de elementos políticos, económicos y socioculturales, de los cuales destacamos dos: primero, la presencia de estructuras internas que absorben las mudanzas capitalistas -aunque sin la posibilidad de desarrollo nacional autónomo- $y$, en segundo plano, la modernización por arriba, propiciada por la influencia externa, de modo que imposibilita una revolución de bases internas del tipo clásico capitalista (Fernandes, 1972; Marini, 1992). Ambos procesos concurren históricamente por la combinación de intereses internos de las clases dominantes y externos de las potencias de economía avanzada. En un movimiento simultáneo de concentración de riquezas internamente y por el flujo incesante de riquezas hacia las potencias dominantes externas. Este fenómeno, Fernandes (1972), lo conceptualiza como "modelo compuesto de la hegemonía burguesa" y caracteriza a los países que no experimentaron una transición clásica para el capitalismo, o sea, que no realizaron una revolución burguesa clásica, sino que procesan el "desarrollo" a través de la articulación entre lo arcaico y lo moderno con vínculos entre la oligarquía y el imperialismo.

9 Aunque las elaboraciones de Fernandes (1972) se refieran al caso particular del Brasil, es posible, guardando las debidas particularidades históricas, económicas y socioculturales, extenderlas para la comprensión de los países latinoamericanos.
La sumisión descrita se vincula a diversos y conocidos mecanismos económicos de transferencia de riquezas de los latinoamericanos, que se acentúan en las últimas tres décadas: se sostienen en el pago de intereses a largo plazo de la deuda externa e interna en gran escala; transferencia masiva de lucros derivados de las inversiones directas y de cartera; compras y adquisiciones de empresas públicas lucrativas y de empresas nacionales con problemas financieros; cobranza de regalías y derechos de licencia sobre una amplia variedad de productos, patentes, mercancías culturales, etc.; balances de cuenta corriente favorables, basados en la dominación de las corporaciones y bancos de los Estados Unidos en la región (Martins, 2011; Wood, 2014).

Un conjunto de políticas ha favorecido la implementación de un exhaustivo programa de privatizaciones, promovido por los gobiernos latinoamericanos; aunado a un aumento continuo de la liberalización, que ofrece protección a las inversiones externas a través de la estabilización monetaria, así como la garantía de infraestructura, subvenciones fiscales y un alto financiamiento estatal. $\mathrm{Al}$ mismo tiempo, expone el atractivo de un extenso acervo de riquezas naturales, mercados internos nada desdeñables y fuerza de trabajo numerosa y barata disponible en la región. Es necesario advertir que el conjunto de estas políticas se implementa con variada intensidad y amplitud en los países latinoamericanos; siendo posible apuntar, a modo de ejemplo, una sensible reducción de las privatizaciones en la primera década y media de este siglo en Argentina, Brasil y Bolivia.

Otro aspecto importante, permeado por el discurso de la "reforma del Estado", que se inicia en los años 1990, se observa en el desmantelamiento del aparato estatal y viene reduciendo el número y los derechos de los trabajadores estatales que lo administran directa e indirectamente. $\mathrm{Al}$ mismo tiempo, esas políticas complementan la insistente mercantilización del acceso a los bienes sociales, como educación, salud y jubilaciones. Esas medidas económicas son implementadas de forma heterogénea y pertinaz en América Latina, pues hacen parte del conjunto de políticas neoliberales.

Aunque los gobiernos progresistas de este siglo 
hayan buscado en la integración regional ${ }^{10}$ en el caso de Brasil es importante destacar la asociación comercial-económica con Rusia, India, China y África del Sur (BRICS)- caminos para políticas soberanas, la actual etapa parece volver a caracterizarse por la reducción drástica del grado de libertad en la perspectiva de construir un proceso autónomo y soberano de consolidación de los Estados nacionales dependientes, actualizando condiciones clásicas del período colonial (Sampaio, 1999; Martins, 2011; Boron, 2012). Entre diversos aspectos de esa relación jerárquica, se destaca una de las funciones estratégicas del Estado que viene siendo progresivamente dejada de lado, la denominada Seguridad Nacional. Pues se vislumbra la progresiva instalación de bases militares estadunidensesenterritoriolatinoamericano, aliado a un creciente desmantelamiento de las fuerzas armadas nacionales. Así, ante movilizaciones que puedan amenazar la legitimidad de los gobiernos -no consiguiendo controlarlas dentro de las reglas del juego institucional vigente- los países latinos se encuentran a la merced de las denominadas "fuerzas multilaterales", que se difunden en el escenario internacional"

Enestostérminos, labúsquedaporlaprofundización de la dependencia económica y política de los países latinoamericanos, trasladando el poder decisorio de las políticas nacionales en beneficio del capital internacional -rehén del capital financiero-, puede ser interpretado como una nueva onda de un proceso recolonizador ${ }^{12}$. Las tentativas de construcción de "bloques de libre comercio"

10 Entre las experiencias importantes, se encuentran las iniciativas que buscaron construir: la Alianza Bolivariana para los Pueblos de Nuestra América - Tratado de Comercio de los Pueblos (ALBA); la Comunidad de Estados Latinoamericanos y Caribeños (CELAC) y el Mercado Común del Sur (MERCOSUR).

11 Consultar Ceceña (2005) y Palau (2011), así como la ya referida obra de Boron (2012).

12 La heterogeneidad de ritmos y conflictos que devienen de esa ofensiva imperialista se relaciona con la connivencia de los gobiernos nacionales en coyunturas específicas en los países latinoamericanos. El caso más evidente de esa invectiva es el de Venezuela, amenazada por el gobierno estadunidense con la posibilidad de utilizar la vía militar para desplazar un presidente electo democráticamente (Dominguez, 2017). comandados por un país hegemónico (por ejemplo, el Tratado de Libre Comercio de América del Norte (TLCAN), el Acuerdo Transpacífico de Cooperación Económica (en inglés Trans-Pacific Patnership (TPP), etc.) parecen reciclar la figura del "exclusivo comercial", remitiendo a la relación colonial que dividía el mundo en "zonas de influencia".

\section{La permeabilidad de las directrices de las políticas públicas en los países latinoamericanos}

Al estudiar el papel del Estado como promotor de las políticas públicas es necesario considerar la complejidad del ejercicio del poder en la sociedad de clases contemporánea. En ese espectro, la selectividad estructural a partir del Estado visa dar cuenta de la diversidad de configuraciones que asumen las fuerzas en su comando y, relacionada con las mismas, las políticas públicas. Esa selectividad estructural es la transcripción en el conjunto de instituciones estatales de las capacidades que las fuerzas políticas alcanzan en una dada coyuntura para realizar sus estrategias e intereses a través del acceso a espacios de poder en el seno del Estado (Jessop, 1999). Esto implica que las directrices hegemónicas de las políticas públicas -lo cual caracteriza la heteronomía de los países latinoamericanos- son "filtradas" por las correlaciones de fuerzas coyunturalmente instaladas en el gobierno, el juego de intereses derivados de la composición del bloque en el poder y la intensidad de las fuerzas sociales organizadas.

La diversidad de formulaciones e implementaciones que las políticas públicas asumen no anulan el carácter de clase, demarcadas por relaciones infraestructurales territoriales. Al resaltar que se trata de una relación social no deja de estar sumergida en las relaciones capitalistas (Jessop, 2015).

El ejercicio del poder estatal implica estrecha relación con su comando. Así, para analizar la dinámica del poder estatal considerando las transformaciones desde el inicio de este siglo es indispensable considerar la composición guber- 
namental en los países de América Latina. En ese sentido, debe innegablemente indagarse por las relaciones del bloque en el poder -o bloque histórico-, proveniente de las elaboraciones de Poulantzas y Gramsci, así como lo que Osorio (2014) denomina como clase reinante ${ }^{13}$-la cual frecuentemente se constituye como coalición gobernante- que puede estar parcial o totalmente asimilada al bloque en el poder.

Considerando las persistentes relaciones políticas subalternas que los países latinoamericanos experimentan en el ámbito del imperialismo con predominio financiero, es indispensable comprender las características particulares que las directrices de las políticas públicas asumen en niveles nacionales. Esas relaciones de dominación están estrechamente vinculadas al papel que las potencias hegemónicas designan en el ámbito de la distribución internacional del trabajo y de la apropiación de la riqueza producida (Wood, 2014).

En ese contexto, durante las últimas tres décadas, los países latinoamericanos -en el núcleo de la geopolítica a la que los mismos son compelidos- construyeron mecanismos estatales que condujeron heterogéneamente a fragilizar las exiguas políticas de protección social, entre ellas se destacan: las que conducen a la precarización del trabajo; a una mercantilización creciente de los medios para satisfacción de las necesidades sociales; a un activismo estatal en la inducción de una estabilidad financiera a nivel macro y creciente privatización de la infraestructura nacional.

Ese conjunto de políticas para América Latina, llevadas adelante con el impulso de las organizaciones denominadas multilaterales (BM y FMI, como actores sobresalientes), fue suministrado diacrónica, persistente e indistintamente en los

13 El concepto de clase reinante proviene de Poulantzas (1970), especialmente en el final del cuarto capítulo de la tercera parte. La clase reinante sería compuesta por presidentes y otros altos cargos de la jerarquía estatal, que pueden ser ocupados por diversos sectores sociales -no necesariamente del bloque en el poder- con los cuales pueden conformar, o no, diversos frentes de poder en función de las coyunturas (Osorio, 2014, pp. 40-51). países de la región (Anghie, 2004; Puello-Socarrás y Gunturiz, 2013). La traducción nacional de estas fue mediada por la correlación de fuerzas y por las características geopolíticas de cada una. La sincronía e intensidad en la implementación de esas directrices neoliberales están vinculadas con las características del bloque en el poder, así como de las coaliciones gubernamentales y principalmente con la fuerza que los sectores subalternos (organizados en sindicatos de trabajadores y en movimientos sociales, ocasionalmente adheridos a partidos políticos) detengan en determinada coyuntura.

Esas mediaciones dinámicas permiten delinear la arquitectura de las políticas públicas en el contexto contemporáneo. En ese ámbito analítico, las políticas públicas contemplan todo aquello que el Estado hace o deja de hacer en la relación del capital con los trabajadores. La extensión e intensidad de la mediación estatal es una función de la correlación de fuerzas geopolíticas nacionales -sin relegar la heteronomía-, considerando al Estado construido como espiral propulsora de los imperativos de la reproducción del capitalismo, que a través de diversos mecanismos sociales expropia a los trabajadores, la mayoría del pueblo.

En períodos en los cuales los cambios de gobiernos permiten significativas transformaciones en la composición social de la clase reinante -esto es, los sectores sociales que acceden al gobierno- las políticas provenientes del Estado pueden procurar el atendimiento coyuntural de las demandas sociales de sectores históricamente preteridos o, como acontece recurrentemente, de los sectores con mayor capacidad reivindicativa. En el ámbito de las políticas públicas -que serían las políticas estatales relacionadas con la cuestión social- para apuntar algunos ejemplos, los estados argentino y brasileño focalizaron la atención en el alivio de la pobreza ${ }^{14}$, delegando tendencialmente al mercado el suministro de los servicios.

Si consideramos que la arquitectura y el funcionamiento del Estado es indisociable de la reproducción del capitalismo, esto significa, en

14 Para una visión panorámica consultar Cecchini y Madariaga (2011), Paz (2010) o Stampini y Tornarolli (2012). 
esencia, que aunque asuma variadas facetas como consecuencia de sus crisis económicas y políticas coyunturales, la riqueza socialmente producida se sigue concentrando en pocas manos. Al mismo tiempo, su heteronomía se presenta con fuerza en el diseño del Estado en la periferia; nos referimos a las interferencias significativas que el país hegemónico y sus estructuras jerárquicas ejercen en el proceso decisorio de las acciones estatales (Fernandes, 1981b, pp. 88-98; Harvey, 2004). Esta subordinación de los países latinoamericanos, con significativos matices en cada uno de ellos, puede ser mejor comprendida considerando la dinámica del imperialismo y su contemporaneidad (Wood, 2014). En resumen, se presenta como doble determinación a la que están sometidos los países latinoamericanos, internamente, como resultado de las tensiones de clase dentro de sus fronteras nacionales $y$, externamente, debido al rol asignado por la geopolítica mundial -estas directivas heterónomas pueden sobreponerse, reforzando o confrontando, inclusive atenuando, coyunturalmente las correlaciones de fuerzas nacionales-. La sincronía e intensidad en la implementación de esas directrices neoliberales están vinculadas con las características de los sectores dominantes, así como de la clase reinante y, principalmente, con la fuerza que los sectores subordinados (sindicatos de trabajadores y movimientos sociales) posean en determinado momento.

\section{Progresismos latinoamericanos en los albores del siglo XXI}

En la última década del siglo pasado los países de la región soportaron un intenso ajuste fiscal, que privilegiaba abiertamente el pago de las grandes deudas externas, restringiendo sueldos y derechos laborales, lo cual contribuyó a la concentración acentuada de las rentas y aumentó profusamente la pobreza en los países de la región. Un amplio programa de privatizaciones se diseminó por las empresas estatales que suministraban servicios a la población de forma subsidiada (energía eléctrica, agua, telefonía y alcantarillado de forma general), así como las de siderurgia, minería y una variedad de empresas consideradas estratégicas para una concepción estatista de de- sarrollo. El denominado ajuste fiscal consiste en un conjunto de mecanismos económicos y sociales, que los gobiernos se comprometen a realizar para pagar intereses y servicios de los préstamos a las instituciones financieras -en condiciones impuestas por ellas- y en detrimento de políticas públicas estatales (Pereira y Pronko, 2014). Esas políticas neoliberales ortodoxas incitaron sendas reacciones populares en diversos países de la región (Argentina, Brasil, Ecuador, Perú, Bolivia, Honduras y Nicaragua, para citar algunos), que en la década subsecuente expresaron, en las elecciones, su protesta ante la situación de precarización de las condiciones de vida.

El crecimiento de las movilizaciones sociales e incremento delapoyo popularalas organizaciones partidarias progresistas, de izquierda y centroizquierda, permitió que alcanzaran diversos gobiernos nacionales. En las regiones andinas esa efervescencia organizativa tiene preponderancia en los pueblos indígenas y se destacan en Bolivia, Ecuador y Perú, así como en Centro América, con la lucha de los neozapatistas como símbolo de la incansable lucha indígena en esa región. Ante el estremecimiento que esta reacción social alcanzó, deponiendo numerosos presidentes y llegando a minar la legitimidad institucional en algunos países, la asunción al poder de gobiernos próximos a las demandas populares y el establecimiento de un conjunto de políticas económicas permitió restablecer el funcionamiento estatal. Estos gobernantes implementaron políticas sociales que amortiguaron, por una década aproximadamente, las protestas sociales y promovieron nuevos espacios de participación política, incluyendo frecuentemente movimientos sociales como interlocutores.

Entre esos gobiernos pueden ser citados los de Chile (con la Concertación ${ }^{15}$ y Bachelet), de Argentina (con los Kirchner), Bolivia (Evo Morales), Ecuador (Rafael Correa), Venezuela (Hugo Chávez y Nicolás Maduro), Paraguay (Fernando Lugo), Brasil (Lula da Silva y Dilma Rousseff), Uruguay (Tabaré Vásquez y José Mujica), Nicara-

15 La Concertación fue una coalición de partidos de izquierda, centro-izquierda y centro, que gobernó a Chilé entre el 11 de marzo de 1990 y el 11 de marzo de 2010. 
gua (Daniel Ortega) y Salvador (Mauricio Funes y Salvador Sánchez Cherén). No es posible afirmar que estos gobiernos implementaron políticas económicas previamente combinadas, pues se observa una variedad significativa de rumbos que han adoptado con la intención de atender las demandas sociales, principalmente de los estratos más empobrecidos y organizados de sus sociedades. Esos gobiernos fueron frecuentemente considerados post-neoliberales, como si hubiesen superado las políticas liberales que caracterizaron al período precedente, pues la intervención estatal generó mejorías sensibles en la situación social de la mayoría de la población (McDonald y Tuckert, 2009). Se diferenciaron, sin embargo, por crear una diversidad de políticas sociales de compensación a las fallas del mercado (de viviendas y/o de rentas entre las más frecuentes); presentando en algunos casos, simultáneamente, estrategias de cuño keynesiano en lo que se refiere a las infraestructuras nacionales, sin que se observe, al mismo tiempo, un proceso manifiesto de industrialización (Carcanholo, 2014).

Esa coyuntura se inscribe en la dinámica que el sistema internacional experimenta desde la última década del siglo pasado, en la que se destaca la creciente relevancia de China a partir del inicio de este siglo. El escenario geopolítico se reacomoda en función de su atracción de parte considerable de la producción industrial de los países periféricos, así como también de los centrales, lo cual contribuyó a un proceso de reprimarización en los países latinoamericanos ${ }^{16}$. El extractivismo, sea en la minería, en los combustibles fósiles o en el sector agropecuario, reasume paulatinamente un papel destacable en la producción contemporánea en la región. Ese aspecto condujo a la región a retomar su tradicional perfil agroexportador y minero, ahora aliado al de exportador de hidrocarburos, carac-

16 A ese respecto, Sanahuja (2016), afirma que "la región experimentó un intenso proceso de "reprimarización" de su canasta exportadora. En 2014, las materias primas representaban más del $80 \%$ de las exportaciones totales de nueve países (Bolivia, Chile, Colombia, Ecuador, Guyana, Panamá, Paraguay, Perú y Venezuela) y entre 60 y $80 \%$ en otros cinco (Argentina, Brasil, Guatemala, Nicaragua y Uruguay). En otros países, esa proporción se situaba por debajo del $50 \%$, con México en la posición más baja: 21,8\%" (p. 54). terísticas que han sido asociadas a un supuesto neodesarrollismo (Gudynas, 2010; Bruckmann, 2012). Antiguos dispositivos de reproducción de desigualdades en niveles mundiales ejercen mayor presión en esta coyuntura, como la desigualdad de valores entre productos primarios e industrializados; sumados al abismo entre los pocos países que detienen los conocimientos y medios materiales de automación y digitales, que redunda en la jerarquizada red de funcionamiento de la financiarización del capital. El escenario bosquejado se realiza sumergido en una insidiosa hegemonía de las reglas implacables del capital financiero, que, con contadas excepciones, interfieren sistemáticamente en las políticas nacionales. El estímulo de las políticas extractivistas permitirá el fortalecimiento gradual de antiguas y nuevas oligarquías detentoras de las tierras latinoamericanas. Aun así, la disponibilidad de mayores recursos durante esos gobiernos progresistas, provenientes de la valorización de las materias primas, diseminó la ilusión de una "primavera social".

En el transcurso de los gobiernos progresistas, las crecientes contradicciones del modelo neodesarrollista serán evidenciadas: al fortalecimiento, a través del financiamiento estatal, de los sectores involucrados con el extractivismo -agropecuario, combustibles fósiles y minería- se oponen los intereses de los movimientos sociales que luchan por la tierra (indígenas, campesinos sin tierra y quilombolas ${ }^{17}$ ). Precisamente aquellos sectores que han sobresalido en la asunción de los gobiernos progresistas serán gradualmente alejados de su interlocución. Esa situación conlleva a un menoscabo paulatino de la participación política (Miguel, 2017). Si al comienzo de esas administraciones proliferan los mecanismos participativos en la gestión pública, en el transcurso van perdiendo su poder decisorio hasta un retorno a una centralización en el Poder Ejecutivo, con una aproximación al tradicional bloque de poder.

Desde el punto de vista de las políticas públicas, la plasticidad inicial del Estado al aceptar

17 Generalmente se utiliza también el término de cimarrones para referirse a las comunidades afrodescendientes. 
las reformas provenientes de los sectores sociales relegados, ha llevado a una lectura optimista, como si no hubiese retorno. La difusión de políticas de complementación de ingresos ha sido una marca general de ese proceso de reaproximación de las masas a los gobiernos, aliados, en algunos países, a una contracción considerable de las tasas de desempleo y aumentos de los sueldos básicos, lo que repercutió en una ampliación del mercado de consumo interno (CEPAL, 2016). Una diversidad de políticas buscó aumentar el acceso a la educación y a la salud, al mismo tiempo en que se ha visto crecer la mercantilización de la oferta de esos servicios. Nos referimos a la proliferación de escuelas y universidades privadas, que con incentivos estatales ganaron espacios significativos en la mayor parte de los países latinoamericanos (De Oliveira Borges y Tomás de Aquino, 2013). Diversos mecanismos en el ámbito de la salud han expandido la creación de empresas privadas que atienden a la población, tanto con la delegación de la gestión de hospitales como del financiamiento que beneficia a los sectores privados para el acceso a tecnología de punta; además el aumento de los planes de salud costeados por sus beneficiarios, contribuyendo con la mercantilización de la vida.

Una característica destacable en este período es la creación de mecanismos jurídicos-institucionales de acceso de campesinos y comunidades étnico-raciales (indígenas y afrodescendientes) a las políticas estatales, principalmente la educación. Las crecientes demandas de género fueron también incorporadas en la institucionalidad latinoamericana, invariablemente asincrónica y de forma heterogénea en ámbitos nacionales y subnacionales.

El fortalecimiento del mercado interno en la mayoría de los países de la región se relaciona con una abundante disponibilidad de créditos para los varios segmentos sociales anteriormente excluidos. Fueron creadas también políticas estatales para el financiamiento de viviendas, particularmente para estratos de baja renta. Heterogéneamente, los sectores, que durante mucho tiempo habían sido mar- ginalizados de la distribución de la renta, disfrutaron de dosis de bienestar, mediadas por el consumo y por una incipiente intervención estatal.

Es indispensable registrar que ni en los periodos de auge neo desarrollista el Estado dejó de lado o se contrapuso a las directrices neoliberales. Salvo algunos casos puntuales -en Argentina, la reestatización de Yacimientos Petrolíferos Fiscales (YPF); en Bolivia, el proceso de estatización de empresas relacionadas con el petróleo o las empresas de comercialización del agua; para citar algunos-, el rol de los Estados latinoamericanos ha sido de incentivo al sector privado, incluso utilizando intensamente los fondos públicos. Los gobiernos progresistas financiaron empresas vinculadas a los sectores extractivistas, así como las que proveen infraestructura para transportar esos productos o para poder extraerlos (como en el caso de la minería).

Así, en este análisis es posible considerar que los países latinoamericanos presentan en el contexto de las directrices neoliberales vigentes, una marcada heterogeneidad en su asimilación. En ese sentido, a grosso modo, se observa que la incidencia del estado en las políticas públicas fue más intensa en Venezuela, Bolivia y Ecuador, ya que en esos países la población tuvo una marcada movilización política para la ascensión de gobiernos progresistas, conquistando acceso a bienes sociales; ya en Brasil, Argentina y Uruguay, durante el periodo en estudio, se observan mejorías en la distribución de la renta, perceptible reducción de la pobreza y/o aumento del consumo, aunados al intervencionismo activo del Estado para el aumento del acceso a las políticas públicas. Los periodos de gobiernos progresistas en Chile, a pesar de sus tentativas y de las movilizaciones sociales, no han conseguido revertir las directrices neoliberales de sus políticas públicas. En el caso de México, que no puede ser incluido en el intervalo progresista, no se asiste a avances en el acceso a las políticas públicas: el "empate catastrófico" entre clases dominantes y sectores dominados, conlleva a la militarización y criminalización de la protesta social. 


\section{Transiciones al pasado}

En el último cuartil del siglo pasado, las utopías emancipadoras para la mayoría de la población se deparaban con la necesidad preeminente de su profundización como prevención ante una nueva onda recolonizadora. Esta última viene siendo victoriosa, aunque de forma mediada y heterogénea, en los países latinoamericanos: es posible observar que diversos indicadores sociales y el acceso a políticas públicas educacionales y de salud han mejorado, al mismo tiempo en que las políticas estatales de jubilación han sido paulatinamente mercantilizadas, tendencia que asola permanentemente a las políticas sociales estatales.

Así, la dinámica de la primera década y media de este siglo en América Latina puede ser pensada a partir del Estado como indisociable de la reproducción del capitalismo, pues, a pesar de las crisis económicas y políticas coyunturales, la riqueza socialmente construida tendencialmente se concentra. Si bien es cierto que para el final de la primera década de este siglo, un significativo número de latinoamericanos tenían gobiernos progresistas -que de manera general incentivaron el acceso a políticas estatales y promovieron el consumo de masas- ese interregno ocasionó escasas transformaciones estructurales que propicien perspectivas favorables para el acceso a los bienes sociales. En ese trayecto -del inicio de las experiencias progresistas hasta la mitad de la segunda década de este siglo-, se observa una disminución de la participación política con relación al Estado, sumado al fortalecimiento de sectores económicos y culturales que defienden una sociedad excluyente. La misma que se creía superada.

En ese contexto es indispensable tener presente, como afirma Harvey (2009), que el neoliberalismo es el proyecto de las clases dominantes en el imperialismo financiarizado, como también apuntaba Ianni (2004). En los países periféricos, como es el caso de los latinoamericanos, el bloque en el poder -compuesto por las burguesías nacionales (comerciales, agropecuarias e industriales)- viene desempeñando el rol de socio menor de las burguesías hegemónicas mundial- mente, el cual busca dominar nuevamente la clase reinante.

Los gobiernos de coalición progresista que tiñeron el mapa latinoamericano en la última década y media no consiguieron, quizás ni pretendían, transformar los fundamentos de la apropiación de la riqueza. Impulsados por la fuerza de movimientos sociales y de trabajadores implantaron numerosas políticas compensatorias, que atenuaron la desigualdad social y permitieron el acceso al consumo de sendas camadas sociales. Dicho transcurso fue realizado en complicidad o, más frecuentemente, con la vigía constante de los sectores económicos dominantes. Estos últimos, al percibir la dinámica del sistema internacional y el alejamiento de los movimientos sociales y sindicales que los apoyaban ${ }^{18}$, crearon mecanismos institucionales para el retorno al gobierno y la profundización del neoliberalismo. Al mantener la materialidad de la hegemonía del bloque histórico intacta ${ }^{19}$-Poder Judicial, fuerzas policiales, conglomerados de comunicación oligopólicos y, en algunos casos, Poder Legislativolas minorías nacionales, asociadas a los intereses imperialistas, retornan al poder del Estado para una nueva investida neoliberal.

Gradualmente, en esta década, es posible verificar la arquitectura heteronómica de los países latinoamericanos. El recrudecimiento de la división internacional del trabajo conduce a los gobiernos latinoamericanos a la aplicación de los imperativos neoliberales y al aumento tendencial de la coerción como mecanismo para modelar la cohesión. La proliferación de gobiernos asociados al imperialismo parece ser el escenario prospectivo. A pesar de que los movimientos sociales y sindicales han pasado por cooptaciones y crecientes represiones, la coyuntura despliega un nuevo momento de intensos conflictos que eventualmente retomará las luchas por un horizonte igualitario.

18 Este proceso no se desenvuelve homogéneamente en América Latina, así como tampoco puede afirmarse una conclusión de esa dinámica.

19 Una vez más es necesario enfatizar diferencias: el caso de Brasil es el que más se aproxima de la descripción y los que se encuentran más distantes son Bolivia y Venezuela. 
Guillermo Alfredo Johnson • Marcos Antonio da-Silva

\section{Referencias}

Amin, S. (2001). Imperialism and Globalization. Monthly Review, 53(2), 6-24.

Anghie, A. (2004). Imperialism, Sovereignty and the Making of International Law. New York, US: Cambridge University Press.

Antunes, R. (2011). O continente do labor. São Paulo, Brasil: Boitempo.

Ayerbe, L. F. (2002). Estados Unidos e a América Latina: a construção da hegemonia. São Paulo, Brasil: Editora UNESP.

Boron, A. (2012). América Latina en la Geopolítica del imperialismo. Buenos Aires, Argentina: Luxemburg.

Boron, A. (2003). Estado, capitalismo y democracia en América Latina. $7^{\mathrm{a}}$ ed. Buenos Aires, Argentina: CLACSO.

Brenner, N., Peck, J.y Theodore, N. (2010). After Neoliberalization? Globalizations, 7(3), 327-345. http:// dx.doi.org/10.1080/14747731003669669

Bruckmann, M. (2012). Recursos naturales y la geopolítica de la integración sudamericana. Lima, Perú: Instituto Perumundo, Fondo Editorial J.C. Mariátegui.

Carcanholo, M. (2014). Desafios e perspectivas para a América Latina do século XXI. Argumentum, 6(2), 6-25.

Cecchini, S. y Madariaga, A. (2011). Programas de transferencias condicionadas. Balance de la experiencia reciente en América Latina y el Caribe. Santiago, Chile: Naciones Unidas - ASDI.

Ceceña, A. E. (2005). Estratégias de construção de uma hegemonia sem limites. En A. E. Ceceña (Ed.), Hegemonias e emancipações no século XXI (pp. 35-55). Buenos Aires, Argentina: Consejo Latinoamericano de Ciencias Sociales.

CEPAL (Comisión Económica para América Latina). (2016). Panorama de la inserción internacional de las economías de América Latina y el Caribe, (LC/G.2697-P). Recuperado de http://repositorio.cepal. org/handle/11362/40744

CEPAL (Comisión Económica para América Latina) y OXFAM. (2016). Tributación para un crecimiento inclusivo, (LC/L.4159). Recuperado de http://repositorio.cepal.org/handle/11362/39949

Chesnais, F. (1998). A Mundialização Financeira: Gênese, Custos e Riscos. São Paulo, Brasil: Xamã.

Chesnais, F. (2003). A 'Nova Economia': uma conjuntura própria à potência econômica estadunidense. En F. Chesnais, G. Dumenil, D. Levy e I. Wallerstein (Eds.), Uma Nova Fase do Capitalismo? (pp. 43-70). São Paulo, Brasil: Xamã.

De Oliveira Borges, V. y Tomaz de Aquino, E. (2013). Ensino Superior à ordem do Capital Internacional. Revista GUAL, 6(2), 22-32. http://dx.doi.org/10.5007/1983-4535.2013v6n2p22

Documento Informativo da OXFAM 210. (2016). Uma economia para o 1\%. Resumo. Recuperado de www.oxfam.org 
Dominguez, F. (2017). Trump and Latin America: continuity and change: Trump's chaotic foreign policy signals more difficulties for the left in Latin America. Soundings: A journal of politics and culture, 66, 90-101. Recuperado de http://www.muse.jhu.edu/article/668241

Fernandes, F. (1972). Sociedade de classes e subdesenvolvimento. Rio de Janeiro, Brasil: Zahar.

Fernandes, F. (1979). Apontamentos sobre a "Teoria do Autoritarismo". São Paulo, Brasil: Hucitec.

Fernandes, F. (1981a). Poder e contrapoder na América Latina. Rio de Janeiro, Brasil: Zahar.

Fernandes, F. (1981b). Capitalismo Dependente e Classes Sociais na América Latina. Rio de Janeiro, Brasil: Zahar Editores.

Gudynas, E. (2010). La ecología política de la crisis global y los límites del capitalismo benévolo. Íconos, 36, 53-67. https://doi.org/10.17141/iconos.36.2010

Harvey, D. (2004). O novo Imperialismo. São Paulo, Brasil: Loyola.

Harvey, D. (2008). O neoliberalismo: história e implicações. São Paulo, Brasil: Loyola.

Harvey, D. (2009). ¿Estamos realmente ante el fin del neoliberalismo? Recuperado de http://herramienta.com.ar

Ianni, O. (2004). Capitalismo, violência e terrorismo. Rio de Janeiro, Brasil: Civilização Brasileira.

Jessop, B. (2015). The State - Past, present, future. Cambridge, UK: Polity Press.

Jessop, B. (1999). Desarrollos recientes en la teoría del Estado - enfoques, problemas, agendas. Bogotá, Colombia: El Siglo del Hombre, Universidad Nacional.

Johnson, G. A. y Silva, M. A. (2016). Estado e diretrizes das políticas públicas na contemporaneidade latino-americana. En G. A. Johnson y M. A. Silva, América Latina contemporânea: espectros, diversidades e seletividades (pp. 11-29). Dourados, MS, Brasil: Editora UFGD.

Lapavitsas, C. (2011). Theorizing financialization. Work, employment and society, 25(4), 611-626. https:// doi.org/10.1177/0950017011419708

Lenin, V. (1986). El Imperialismo - Fase Superior Del Capitalismo. Ciudad de México, México: Editora Grijalbo.

Marini, R. M. (1992). América Latina: dependência e integração. São Paulo, Brasil: Página Abierta Ltda.

Martins, C. E. (2011). Globalização, dependência e neoliberalismo na América Latina. São Paulo, Brasil: Boitempo.

McDonald, L. y Tuckert, A. (Eds.). (2009). Postneoliberalism in the Americas. London, UK: Palgrave Macmillan.

Mészáros, I. (2007). O desafio e o fardo do tempo histórico. São Paulo, Brasil: Boitempo.

Mészáros, I. (2011). A crise estrutural do capital. São Paulo, Brasil: Boitempo.

Miguel, L. F. (2017). Resgatar a participação: democracia participativa e representação política no debate contemporâneo. Lua Nova: Revista de Cultura e Política, 100, 83-118. http://dx.doi. org/10.1590/0102-083118/100 
Moniz, L. A. (2005). Formação do Império Americano: da guerra contra a Espanha à guerra no Iraque. Rio de Janeiro, Brasil: Civilização Brasileira.

Osorio, J. (2014). O Estado no centro da mundialização: a sociedade civil e o tema do poder. São Paulo, Brasil: Outras Expressões.

Palau, M. (Ed.). (2011). La dimensión represiva y militar del modelo de desarrollo. Asunción, Paraguay: BASE IS.

Panitch, L. (2000). El Nuevo Estado Imperial. New Left Review (versión española), 3, 5-20. Recuperado de https://newleftreview.org/

Paz, J. A. (2010). Programas dirigidos a la pobreza en América Latina y el Caribe: sustento teórico, implementación práctica e impactos sobre la pobreza en la región. Buenos Aires, Argentina: CLACSO.

Pereira, J. M. y Pronko, M. (Eds.). (2014). A demolição de direitos: um exame das políticas do Banco Mundial para a educação e a saúde (1980-2013). Rio de Janeiro, Brasil: Escola Politécnica de Saúde Joaquim Venâncio.

Poulantzas, N. (1970). Poder político y clases sociales en el estado capitalista. Ciudad de México, México: Siglo XXI Editores S.A.

Puello-Socarrás, J. F. y Gunturiz, M. A. (2013). ¿Social-neoliberalismo? Organismos multilaterales, crisis global y programas de transferencia monetaria condicionada. Política y Cultura, 40, 29-54.

Sampaio, P. (1999). Entre a Nação e a Barbárie: os Dilemas do Capitalismo Dependente em Caio Prado, Florestan Fernandes e Celso Furtado. Petrópolis, Brasil: Vozes.

Sanahuja, J. A. (2016). Regionalismo e integración en América Latina: de la fractura Atlántico-Pacífico a los retos de una globalización en crisis. Pensamiento Propio, 21(44), 29-75. Recuperado de www. cries.org

Schoultz, L. (1999). Estados Unidos: poder e submissão, uma história da política norte-americana em relação à América Latina. Bauru, Brasil: EDUSC.

Stampini, M. y Tornarolli, L. (2012). The Growth of Conditional Cash Transfers in Latin America and the Caribbean: did they go too far? IZA Policy Paper - Leibniz Information Centre for Economics, 49, 1-32. Recuperado de https://publications.iadb.org

Suárez, L. (2003). Madre América: un siglo de violencia y dolor (1898-1998). Frankfurt/La Habana, Alemania/Cuba: Editorial ZAMBON, Editorial de Ciencias Sociales.

Wood, E. (2014). O Império do Capital. São Paulo, Brasil: Boitempo. 